\title{
Producing Identity in Collaborative Virtual Environments
}

\author{
$\begin{array}{llll}\text { Kaisa Kauppinen } & \text { Anri Kivimäki } & \text { Taina Era } & \text { Mike Robinson }\end{array}$ \\ Department of Computer Science and Information Systems \\ University of Jyväskylä \\ P.O.Box 35, FIN-40351 Jyväskylä, FINLAND \\ Email:kaikaup@cc.jyu.fi, anrkivi@cc.jyu.fi, taiera@cc.jyu.fi, mike@cs.jyu.fi
}

\section{ABSTRACT}

\section{The usability of Collaborative Virtual Envi-} ronments is a function of technical affordances with the implicit and explicit intentions of users. Intentions can be revealed by 'cyborg ethnography' - a close examination of interactions and conversations conducted in CVE's. Three CVE's are examined ethnographically, for evidence that they have at least some characteristics of societies or social systems, and for the relevance of gender. It is found that social conventions develop around the theme of producing identity, of which gender is one component. There is doubt that such conventions constitute evidence of a 'virtual' social system.

\subsection{Keywords}

Virtual Reality, social conventions, identity, collaborative virtual environment, gender

\section{INTRODUCTION}

Supporting people working in collaborative virtual environments (CVE's) has been an item on the research agenda since the 1980's [15]. Ethnographic research has revealed skilled interaction techniques, e.g. peripheral-awareness, talking-out-loud, glances and overhearing $[10,18]$ as important ways in which people manage complicated working environments. These mundane, easy-to-overlook behaviours have worked as a model for designing, developing, evaluating and researching Groupware and CVE's. The spatial model for CVE's [2] supports these affordances, allowing proximity, overhearing, peripheral-awareness, etc. Salient elements are a spatial environment, possibility to manage social positioning in relation to others, and possibility to

\footnotetext{
Permission to make digital or hard copies of all or part of this work for personal or classroom use is granted without fee provided that copies are not made or distributed for profit or commercial advantage, and that copies bear this notice and the full citation on the first page. To copy otherwise, to republish, to post on servers or to redistribute to lists, requires prior specific permission and/or a fee.
}

O1998 ACM 1-58113-019-8/98/ 0011/ \$5.00 express intentions through gestures and facial expressions. [3]. It has also been suggested that CVE's require good setup and maintenance of connections, double-level language and multi-functionality in order to support work $[4,11,14]$. However, ability to modify the environment and its artefacts is not generally considered important.

CVE's for entertainment have become widely available and popular, and increasingly technically sophisticated in recent years. They offer similar features to interactive Groupware. Ethnographic studies of social conventions that develop in them, and the design implications, were pioneered by Bowers et al [3] and are interestingly developed by Becker, Jeffrey, and Mark [1,12]. This research aroused our interest in social phenomena in CVE's - especially in the claim that CVE's support virtual societies with at least some characteristics of society as we experience it in everyday life. We wished to add to the new field of "cyborg" research [9], and noted the lack of published work on gender relations. We observed three different virtual worlds with respect a) to established findings; b) gender relations; and c) indications of a viable 'virtual society'. We tentatively established that specific conventions noted by others, and reproduced by us, and our new observations on gender conventions, fit into a pattern. All these conventions are loosely structured by a collaborative process of identity production. However, this process leads away from, rather than towards a viable 'virtual society'. We conclude that the types of CVE we observed do involve social conventions, but are little more than alternative communications channels. It is doubtful whether these types of CVE can indeed support 'virtual societies'.

\section{SOCIAL CONVENTIONS}

The Internet has made possible worldwide sharing of VR's and virtual spaces. Freeware is available at home, work, and in public places like libraries and schools.

This situation creates an interesting mixture of different cultures and boundary conditions. Social interaction in CVE's includes social conventions as existing, regular social practices or accepted rules or usages. Rules are partly explicit (text, or enforced by world managers) but mostly implicit. Becker and Mark [1] (henceforth B\&M) found the following conventions:

- Contacting others: greeting and presenting oneself, leaving and explaining why were common conventions. In 

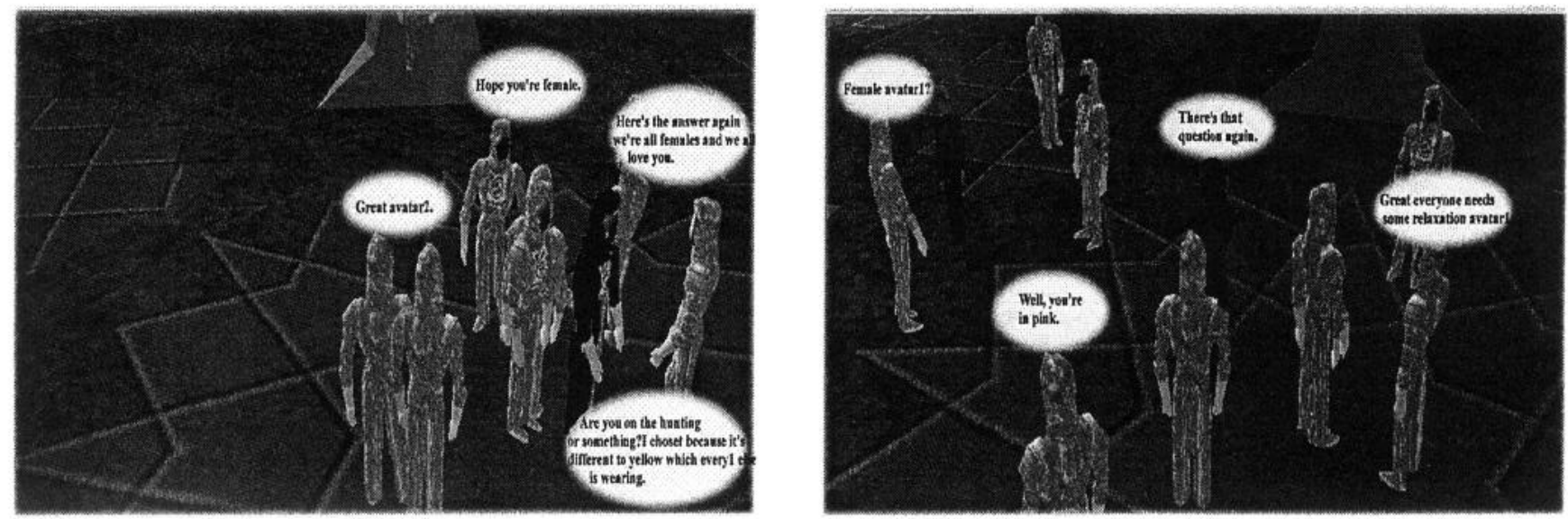

Figs. 1 \& 2 "Ants to Sugar" (female avatar in pink)

this way participants aimed at some shared understanding of their social situations.

- Group interaction: in VR, distances between avatars established group membership and privacy. In text based environments, group membership was often unclear. Private discussion switched to one-to-one text or audio channels, and ignoring outsiders protected privacy.

- Communication: convention of politeness are maintained but gestures and facial expressions were seldom used. Language was descriptively rich "almost in a comic book-like fashion".

- Social positioning: was established by spatial positioning. People defended their own social distances.

- Sanctions on behaviour were not often needed. Cases of rude language or behaviour were sanctioned by ignoring, by verbal or textual 'punishment', or in extreme cases, disconnection.

and conclude that virtual and real world environments have similar social conventions, although reflecting their specific environments. From this point of view, CVE's form a social system. Our research was aimed to re-test these findings, and to extend them to investigate conventions concerning gender. Gender was a significant factor in interaction. Nevertheless, our results, contrary to initial expectations, showed that gender-based behaviours and conventions, along with many of the phenomena described above, were often subordinate to a process of identity construction. This led us to question the link between 'social convention' and 'virtual society'. The first does not necessarily imply the second.

\section{GENDER IN VIRTUAL REALITY}

VR opened new interaction avenues with tailorable avatars which could be combined from elements of animals, artefacts etc. Gender blurring chimeras and cyborgs became available. Individual identity may be variably and variously expressed. Rich, colourful avatars may overcome the naturalistic definitions of male/female, human/machine, human animal etc. Haraway [8] suggested that "Cyborg imagery can suggest a way out of the maze dualism in which we have explained our bodies and our tools to ourselves. This is a dream not a common language, but a powerful infidel heteroglossia."

Individual fantasies, stereotypes, or one's own appearance can be expressed via an avatar. Participants can never be sure about each others' "truthfulness". The story of Julie who became a trusted confidante in women's networks and was, years later, exposed as a male psychiatrist - exemplifies performative possibilities in virtual worlds [17]. This instability of old borderlines can be seen enthusiastically as a possibility for identity growth, of avoiding gender discrimination, or as a threat [13]. Is gender as fluid or unstable as it seems in virtual environments? Why is it that males outnumber females by more than three to one? [17] One obvious effect of gender in 3D environments that has been seen by many, but not previously documented, is the 'antsto-sugar' effect. 'Male' avatars quickly cluster round any 'female' avatar that appears. This is easily seen in figs. $1 \& 2$. Our research addressed whether this and other consequences of gender based representations (names and shapes of avatars) are superficial, or carry over into social conventions in CVE's.

\section{METHODOLOGICAL APPROACH AND RESEARCH SETTING}

The world of "social facts" is accomplished through members' interpretive work - activity through which actors produce and organise the very circumstances of everyday life [6]. Ethnomethodology is a methodological and observational approach to understanding social order. Social structures are locally produced, maintained, and experienced as normal environments. We have already noted research that evidences virtual worlds as social systems. Ethnomethodological analysis focuses on the interactionally unfolding features of social settings and structures, treating talk and interaction as topics for analysis rather than indicators of more sociologically 'important' underlying phenomena [5].

Three different virtual environments (Table 1) were chosen to study social conventions and gender relations: Active Worlds (AW), OnLive!Traveller (OT) and Microsoft NetMeeting (NM).

- AW communication is by text messaging. It is a 3dimensional landscape complete with scenery, realistic 


\begin{tabular}{|l|l|l|l|l|}
\hline Virtual World & Description & Status & Platforms & Size \\
\hline $\begin{array}{l}\text { Active Worlds } \\
\text { (C) 1995-1998 Circle of Fire } \\
\text { Inc. }\end{array}$ & $\begin{array}{l}\text { Multi-user 3D } \\
\text { community with } \\
\text { text }\end{array}$ & Freeware & Windows95/NT & $1610 \mathrm{~Kb}$ \\
\hline $\begin{array}{l}\text { OnLive!Traveller } \\
\text { (C) } 1996 \text { OnLive! Technolo- } \\
\text { gies, Inc. }\end{array}$ & $\begin{array}{l}\text { Multi-user 3D } \\
\text { community with } \\
\text { text \& audio }\end{array}$ & Freeware & Windows95/NT & $4840 \mathrm{~Kb}$ \\
\hline $\begin{array}{l}\text { Microsoft NetMeeting } \\
\text { (C) 1996-1997 Microsoft Cor- } \\
\text { poration }\end{array}$ & $\begin{array}{l}\text { Non-3D CVE for } \\
\text { multi-media com- } \\
\text { munication }\end{array}$ & Freeware & Windows95/NT & $2146 \mathrm{~Kb}$ \\
\hline
\end{tabular}

Table 1.

objects, and generic avatars. Every person has an avatar whose movements are controlled by mouse/arrow keys. People navigate by 'walking' or 'flying', and can take a $1^{\text {st }}$. or $3^{\text {rd }}$. person point of view. There is a teleportation/transportation option for visiting different worlds that works in similar fashion to a web browser's bookmarking. There are two user options: tourist (free) and registered member, where the fee allows users e.g. to have additional features for avatars.

- OT is similar to AW with the addition of live audio to text communication. Access is free. There is a map but no $3^{\text {rd }}$. person view. Users can choose and modify their own 3D avatar $(30+$ alien, animal, and human characters are available).

- NM was included for contrast, as a CVE without 3D. Communication possibilities include full/half-duplex audio (depending on sound card capabilities), video-based conferencing (compliant with the ITU H.323 standard), whiteboard, applicalion sharing (Web or Word docs etc.), and text-based messaging. Additionally, NM allows file and sound-clip transfer.

90 hours observations were made in the three virtual environments. 40 hours each were spent in AW and NM, and 10 hours in OT. Researchers did not appear in the on-line environments under the same guise each time: names and avatars were changed. Initially names and avatars were used that did not indicate gender (e.g. Skipper, Rabbit). Later, male and female avatars were used. The observations took place in the Telematic Studio at Jyväskylä University during April 1998. Time was spent on-line at weekends and during the week at different times of the day. The data gathered included saved text files, notes from audio interactions, picture clips from virtual worlds. Observations were focused on the social categories identified by B\&M [1] plus gender. In the examples some names have been changed for privacy protection.

\section{FINDINGS}

In general, our specific observations on greeting, positioning, leaving, etc. confirmed those of $B \& M$. In addition, gender was found be salient, and associated with predictable patterns. However, our analyses and transcripts go beyond $\mathrm{B} \& \mathrm{M}$ in suggesting that interactions and conventions in open virtual worlds are systematically structured by a developing process of identity production. The characteristics of conversation, convention, and behaviour (including gender response) change qualitatively and quantitatively depending on the stage of the identity production process. The watershed, dramatically illustrated by the full transcripts, takes place at a ritual point of real-name exchange. While supporting views $[16,17]$ on cyborg gender ambiguity, the observations also confirm the findings of Bowers et al. [3] that users comport themselves simultaneously in virtual and physical worlds, and much of the aesthetic, moral, and practical achievement lies in managing the intersection.

\subsection{Contacting Others: Greetings \& Acknowledging}

Greeting is an important convention that serves to initiate contact and can influence subsequent interaction [1]. Benford et al [2] make the point that different spaces have different uses. These relate to different social practices that are enacted in those spaces. In virtual worlds, especially chat channels, users need to greet each others to make themselves available for conversation. Our observations confirm that informal greetings (i.e. hi, hello all!) are generally used to initiate conversation; and it is conventional (with strangers or acquaintances). To us, there were few differences with everyday life.

\subsection{Leaving}

Our observations agree with B\&M [1], that a leaving ritual generally indicates engagement and social binding. Several occasions were observed in which a leaving signal resulted in persuasion to stay, e.g. (from AW)

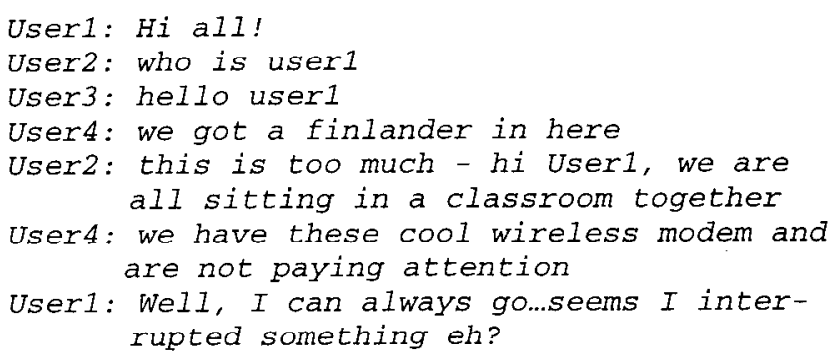


User2: no don' 't go

User3: no, no

User4: user2 1ikes you

In all worlds, long interaction delay could lead to disconnection. Hence the status of avatars was sometimes uncertain: questions such as "Are you still here?" were asked. There could also be 'degrees of presence' if the user e.g. answered the phone without mentioning it to the group [2] On other occasions the avatar or user disappeared unexpectedly. This might have been result of technical problems ${ }^{1}$. Alternatively, in new groups, if the discussion did not interest the user, they could leave without acknowledgement. In general, avatars rarely left voluntarily without saying goodbye.

OT: Audio indicators and a list of users leaving or entering the world were provided.

NM: Poor audio and video connection, and differing equipment caused problems. Leaving and joining were notified by a system-generated message. Characters could leave "everybody in chat" for a private conversation without mentioning it to others.

\subsection{Establishing Group Membership}

B\&M [1] focused on co-present group membership and privacy techniques, and our observations largely agree with theirs. However, identity production indicates another notion of group: people who know each other, whether copresent or not. This depends on recognition, and hence on a certain maturity of identity production. We will deal here with the original membership and privacy phenomena.

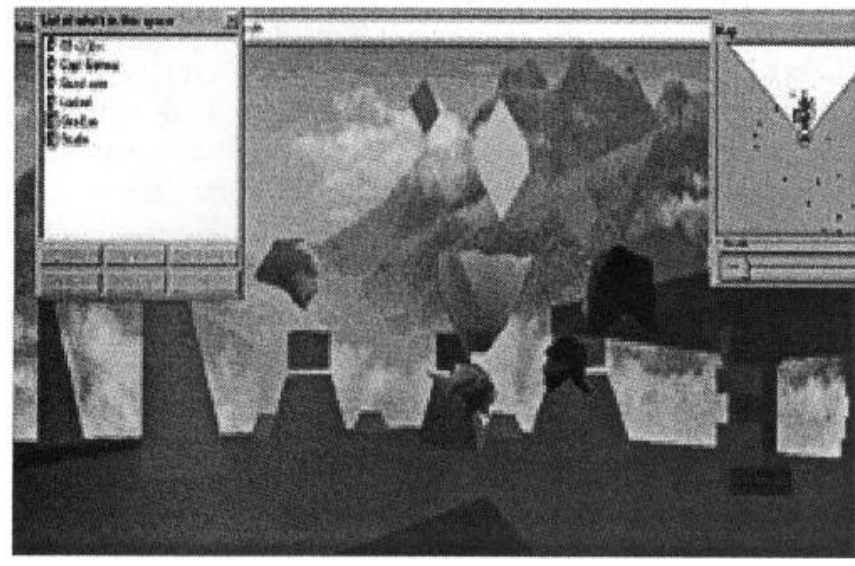

Figure 3 Group in OT

OT: The spatial group was easiest to recognise in OT because it was technically easy to move and manage avatars.

AW: Avatars could be in layers, causing difficulties in identifying both avatars and groups, and additionally the colours of avatar 'suits' are similar. In AW it was difficult

${ }^{1}$ See [7] for a touching account of an attempt to re-establish communication after a technical breakdown. Note this took place in a MUD, a form of CVE that may be exempt from our conclusion that immutable CVE's do not seem to support 'virtual societies'. to follow conversation, because all messages came to the same forum.

NM: Group establishment was accidental (in our observations) or by friends (e.g. student groups). Partners could be chosen from the directory. The system informed the group if other users tried to join. The newcomer was then notified of acceptance/rejection. NM audio/video limits interaction to two partners. This feature makes it impossible to overhear private conversations. Text connections could use "everybody in chat" or "private to" functions.

Our observations supported the finding that common activities or location indicated group membership (at least at a pre-identity level). Avatars flying together counted as a group, sustaining membership by audio or text. A group of more than two persisted if it established a common discussion topic or activity e.g. jumping/flying/dancing. B\&M [1] found that groups of avatars position themselves to form a circle roughly $30 \%$ of the time in $\mathrm{AW}$, and much higher in OT. We found a similar figure of $50 \%$. We agree that it was easier to establish groups in spatial virtual worlds (AW, OT) than in textual worlds (NM).

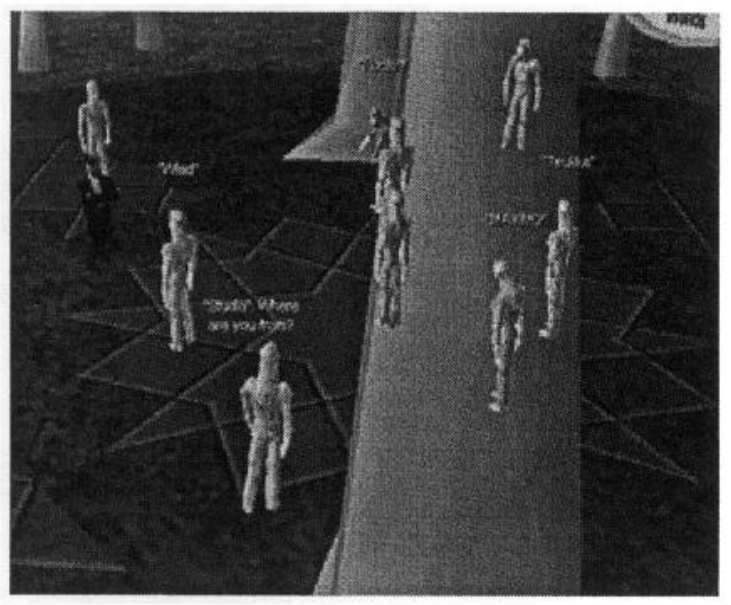

Figure 4. Group 'Circle'

\subsection{Indicating Privacy}

In all worlds users could establish privacy by setting up a different channel. Requests for privacy could be rejected (first example) or accepted (second example) ${ }^{2}$.

user1: I have my speaker turned down.

user2: Oh I see.

user1: My girlfriend doesn't appreciate this.If I talk to men that's o.k. Why don't you give me your email address. I can talk later then.

and

(after changing from using audio to text)

user1: Here we go.

user2: Yes :).

\footnotetext{
${ }^{2}$ There were occasions, similar to these examples, where people wanted to talk in a virtual world from their workplace.
} 
user1: It's better to chat like this. I don't want others to hear what we are talking about.

Privacy could be indicated by language e.g. Dutch, Spanish, Chinese. Trying to divert from one language to another was not appreciated. Requests made in a different language were generally ignored. Thus privacy could be established by language as well as location and channel.

\subsection{Social Positioning and Intimacy}

Do avatars approach each other to converse? Can avatars come too close for comfort? To what extent do position expectations of physical environments transfer to the virtual? B\&M [1] found positive answers to all three questions. Our observations generally supported them.

In AW and OT, avatars assumed face-to-face positions to indicate participation and interest. To achieve privacy two avatars could separate from the group and continue their conversation in a quieter place. In OT this allowed lower audio levels.

In AW and OT if an avatar began text-chat with another at a distance, the other started to approach. When conversing, it was acceptable to come closer, as in real life. In AW and NM, it is not possible to make judgements about appropriate distance. In AW, because of known navigation difficulties, one avatar could walk through another without sexual or physical meaning. In NM, social positioning simply does not exist. On the other hand, in OT position seemed significant: there is a social distance which it is not permitted to cross, as in the following example.

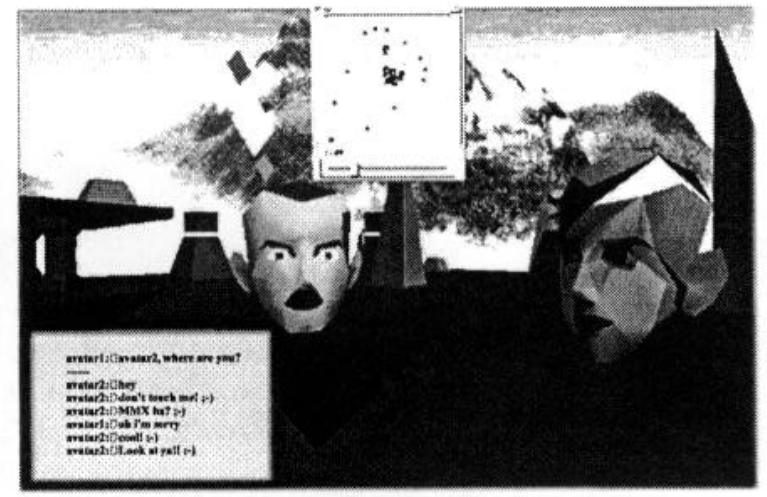

Figure 5 Don't touch me!

\subsection{Sanctions on Behaviour}

"In this category we were interested to explore whether implicit or explicit conventions are not only fulfilled, but whether there exists a mechanism to insure that they are followed" [1].

In our observations, 'bad' behaviour was limited by the technology to offensive language ${ }^{3}$. This was generally sanc-

${ }^{3}$ The exception was in NM where there was a whiteboard with drawing, manipulation, and disposal tools. Here the technology allowed one member to destroy a collective effort, thus making tioned (by disconnecting, ignoring, or by weak or strong responses) although there were many occasions when it was not. In general (anticipating the next section) abusive text was gender related. However, its incidence decreased dramatically from a quasi-norm (especially in NM) to almost nothing as the process of identity production developed.

Our results on sanctions extend those of B\&M [1]. We agree that violations generally attract sanction in the early stages of acquaintanceship - but in the later stages, as in everyday interaction, violation and thus sanctioning all but disappeared. We observed a move from external to internalised regulation of behaviour. Two examples of early stage sanctioning follow.

AW: . In the following example, a group supports a 'weak' member. We see avatar1 is obviously annoyed about the questions of gender. Avatar4 stands next to avatar1, and supports her by generalising the question of gender. The next examples also illustrate that harassment by text in 3D is noticeably weaker than in pure text form.

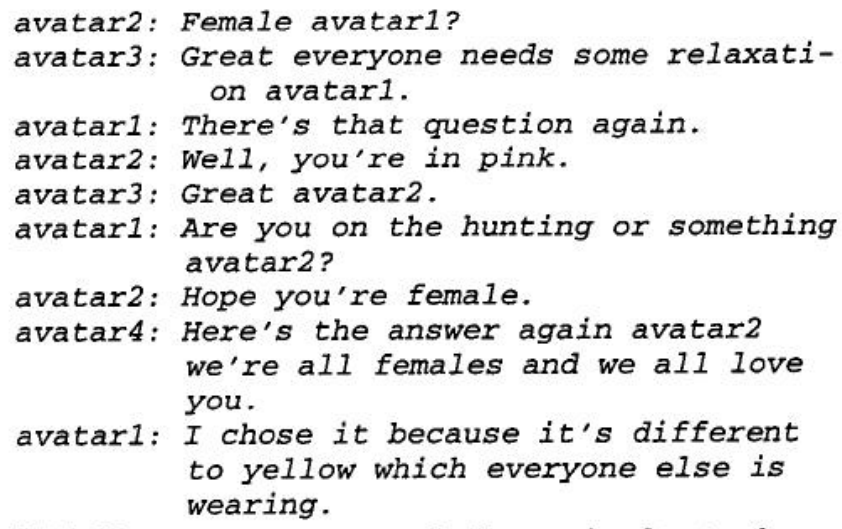

NM: Here we see a not untypical example of text-only sexual harassment. User5 tries a mild sanction and is ignored.

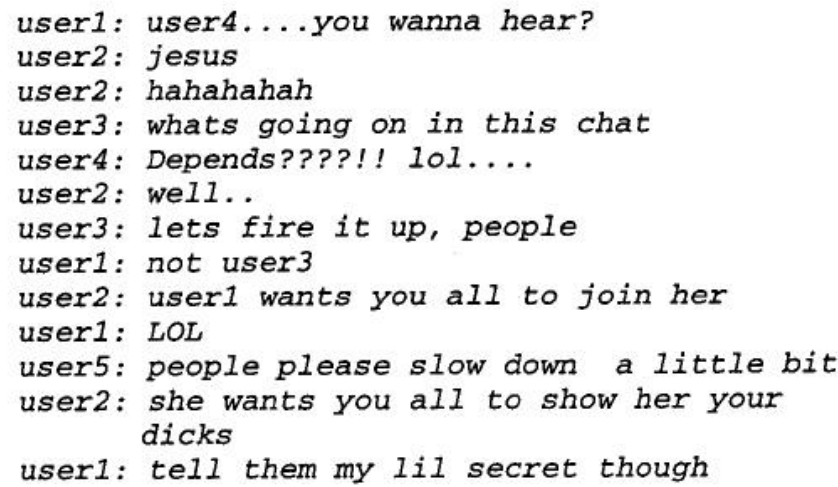

\subsection{Gender Based Behaviour}

The majority of users in virtual worlds are males [17]. When a female enters a world or meeting, she is 'greeted' more than males would be. So in one sense it is an 'advan-

it impossible for the others to continue. This was observed on several occasions, and drew protest from the others. 
tage' to be female, but this may spillover to the 'ants-tosugar' effect. Avatar appearance or colour are quickly seen as indicating gender.

(avatarl enters the world, dressed in pink) avatar2: Female avatarl?

B\&M [1] used gender-neutral avatars, and do not report much rude behaviour. We did observe (and were subjected to) quite a lot of gender-related rude behaviour. A female (avatar) is liable to scxist suggestions. All the authors had more than one experience of sexual harassment. Most of these appeared in $\mathrm{NM}^{5}$, in textual form with no VR or audio. When using audio we experienced little such rude behaviour. We surmise that audio is more personal while text encourages uninhibited fantasy projection onto others. Two sexist behaviour clips from NM text-exchanges follow:

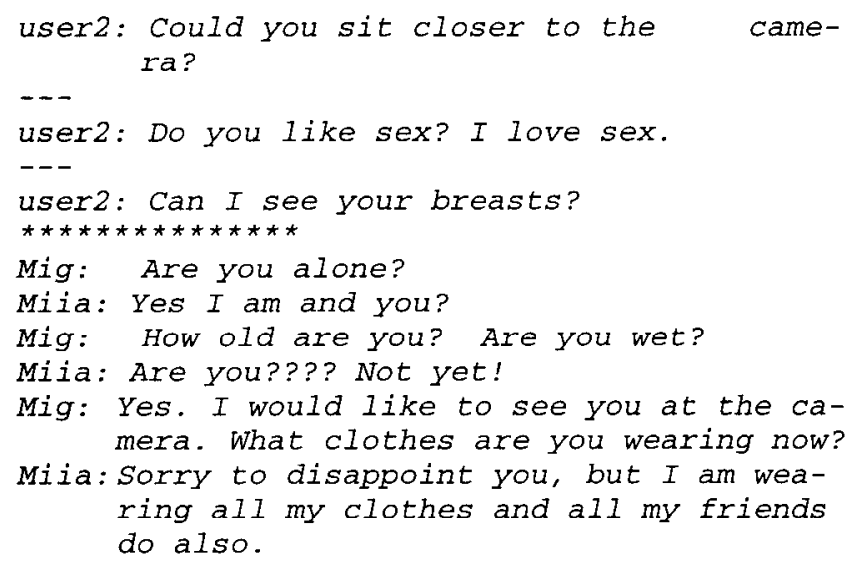

\subsection{Communication}

A social system requires a common language. Language includes gesture and facial-expressions, hymiods, and abbreviations. We saw much 'code' language. If one does not know the meanings of the expressions, one can easily misunderstand the conversation or feel embarrassed. The following example from AW will only be fully comprehensible to the initiated.

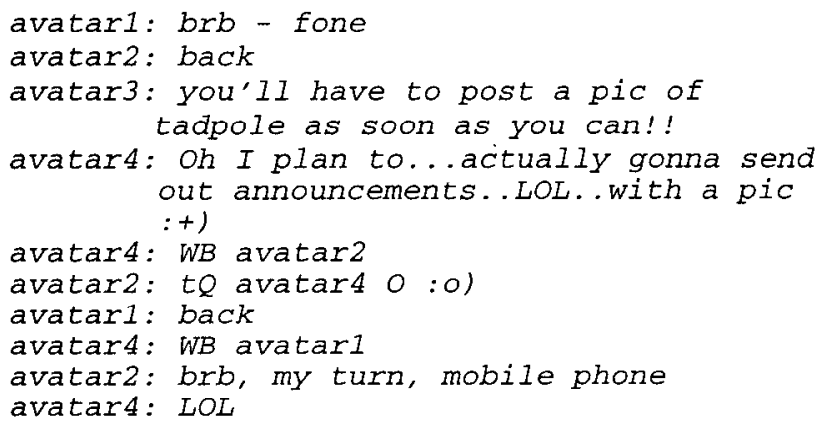

${ }^{4}$ In NM, the comment column added some sophistication: one could show the kind of company one was looking for (e.g. female, business, gay, alone at home).

${ }^{5}$ Although similar behaviours were occasionally found in AW and OT. avatar1: tang TD:o)

avatar3: 101

AW: only supports gestures such as waving, dancing and jumping, not facial expressions. Emotions are usually expressed textually.

OT: supports facial expressions such as happy, normal, angry and surprised, but there is no gesture as OT avatars are mainly faces. However, audio allows a sense of the moods and emotions at the other end. The usual abbreviations etc. are used when interacting via text. Audio is generally preferred, but private issues often dealt through text.

NM: Emotions are expressed in textual form or through audio and/or video. In our observations, NM users preferred text to audio interaction.

We agree with $B \& M$ again, that even where available, body gestures and facial expressions are seldom used. Hymiods (comic like language) are used frequently.

\section{IDENTITY PRODUCTION}

Ninety hours observation produced $100+$ pages of transcript. Analysis revealed a clear developing pattern. Initially all that was given was an avatar or, in NM, an often bizarre name. At this point behaviour/utterances are issued in a social vacuum. Greetings can easily turn to harassment and abuse, and some 'names' indicated this before interaction even started (e.g. "11 inches"). Interaction tended to be very short. Phrases of 3 or 4 words rather than sentences. Complete discontinuity between one utterance and the next. If conversations stumbled past this point, a clear pattern of questioning/information-volunteering evolved.

\section{- $\quad$ are you really female/male?}

- how old are you?

- where are you (city/country)?

- what do you do?

- personal information (hobbies/holidays)?

In this processes, sentences become longer, and start to be interwoven as coherent topics. After some time in such a dialogue, after at least 4 of the questions have been dealt with to the mutual satisfaction of the parties, then (and not before) comes the delicate question of real-name exchange.

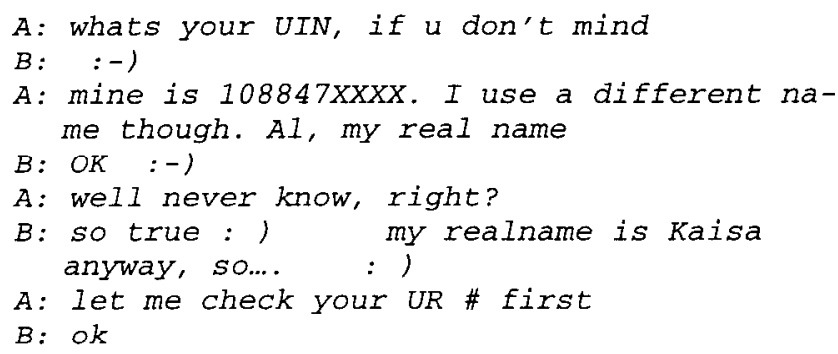

Once this ritual point has been passed (more than a dozen times in our observations) conversations take on a 'normal' form in terms of content (inter-related coherent topics); phrasing (to indicate politeness, mutual respect, humour, 
shared understandings); and syntax (longer text and more standard punctuation).

We can speculate that enough context is first established to support a minimal level of trust. Once this has been repeated with different aspects of users real-worlds, then it is consolidated with the real-name-exchange ritual. After this point (but not before) users are in a position to recognise each other in the future, and (possibly) to meet again. In other words, users are engaging in a process of identity production that is a matches the technical characteristics of the virtual. This is different from introductory interpersonal explorations in the non-virtual world, where sex, age, location (at least) are self-evident.

All the conventions of greeting, group formation, etc. considered earlier can thus be seen as parts of a general process of identity production, which if satisfactorily completed, leads to the name-exchange ritual, and the possibility of recognition and future meeting.

\section{Schematic Representation of Virtual Identity \\ Production Process}

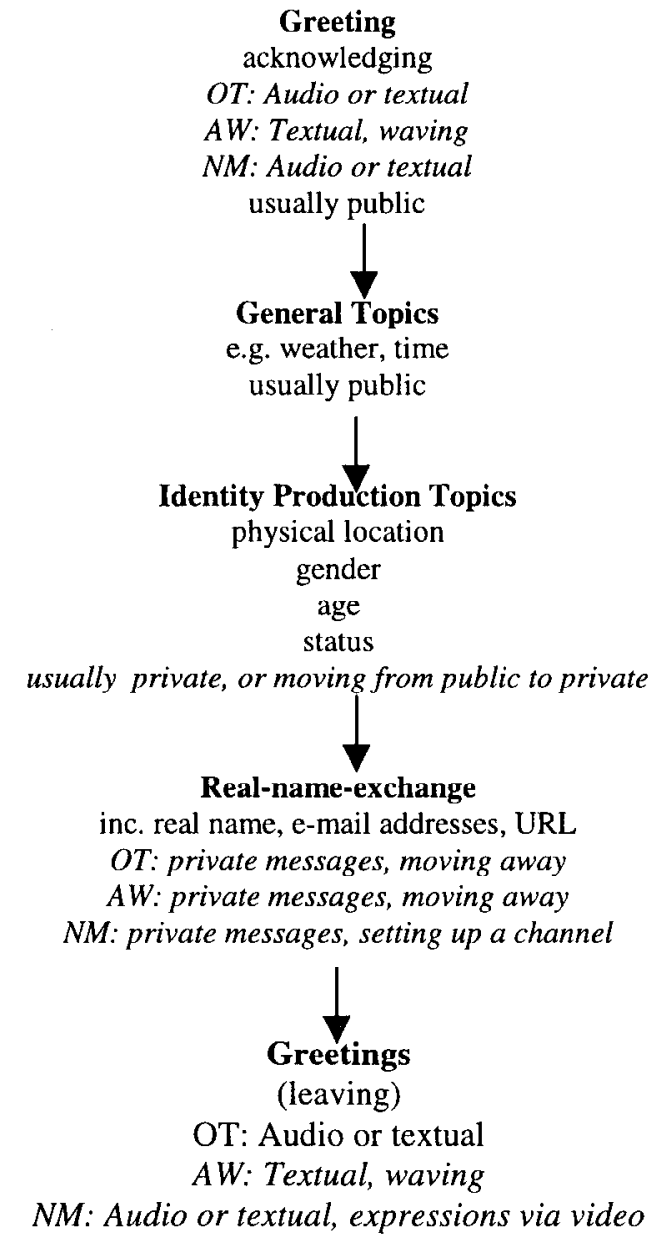

Interactivity implies two conscious agencies in conversation, playfully and spontaneously developing a mutual dis- course, taking cues and suggestions from each other as they proceed. Therefore the flow presented above varies among conversations, yet usually including all the phases emerging as the discourse develops.

\section{DISCUSSION}

Our observations supported our initial intuitions that gender plays a significant role in virtual worlds, and also confirmed the convention detail of B\&M's results. Virtual environments develop social conventions: greeting, acknowledging, and leaving rituals; establishing groups; social positioning and expression of intimacy/privacy; and social sanctions. Some differences were observed: leaving: more users disappeared; groups were formed more frequently; rude behaviour was met more often and not always sanctioned (but decreased dramatically on increased acquaintance); rude behaviours usually occurred in text-alone mode. In addition, we found issues concerned with the overlap of physical and virtual worlds. This sometimes impinged on privacy, but also manifested as working on technical problems while trying to keep conversation going (not always successfully).

In the area of gender, we saw that it is quite impossible to appear without attributed gender in virtual worlds: users are interpreted as, or asked to identify themselves as female/male. Identifying oneself as a female has advantages of ease-of-contact, and disadvantages of harassment. Gender makes a difference in virtual worlds - as it does in real world.

\section{"The cyborg point of view is always about communication, infection, gender, genre, species, intercourse, information, and semiology." (Donna Haraway, 1995)}

Nevertheless, the situation is not as bad as some dialogues make it seem, and Haraway's optimistic perspectives cannot be discounted. Gender-abuse is symptomatic of early, onceoff interactions (and less dangerous than 'bad' barrios in cities). Many gender enquiries are part of a social process of identity construction, along with other contextual information such as age and location. In this respect 'trustworthiness' in virtual worlds is not isolated from the everyday notion, and can be assimilated to it.

However, while concurring in much of the detail of virtual conventions, our conclusion is the opposite of that drawn by B\&M [1], who say:

our results are a first step in suggesting that virtual environments show characteristics that we know to exist in social systems

In our research, virtual worlds were not 'places in themselves' supporting social systems as we usually regard them. The conventions were part of a process of identity production, and the dynamic of that process was to get behind the virtual world to the 'real' person. In this sense, virtual worlds were more like one of their own 'portals' - an avenue of travel from one place to another. Once identity had been produced, the conversations were subject to normal 'social gravitational forces' without any special virtual as- 
pects. Convention formation and identity production were ways of de-virtualising, and effectively reimposing the everyday social on the virtual.

It is worth noting that we draw this conclusion from a study of immutable virtual worlds, where users can do nothing to change, alter, construct, or create their own environments and the constellations of artefacts within them ${ }^{6}$. It would be interesting to carry out similar observations in MUD's, MOO's, and VR's (inc. membership AW) supporting possibilities for the construction and modification of artefacts. Whatever the claims made by others, from our observations, virtual societies as societies-in-themselves (rather than just another set of communication channels) do not appear to be supported by immutable virtual worlds. The CVE design implications of this are rather strong.

\section{REFERENCES}

[1] Becker, B. and G. Mark. Social Conventions in Collaborative Virtual Environments. in Collaborative Virtual Environments '98: CVE'98. 1998. University of Manchester, UK. 17-19 June 1998.

[2] Benford, S., et al., Supporting Cooperative Work in Virtual Environments. The Computer Journal, 1994. 37(8): p. 653-668.

[3] Bowers, J., J. O'Brian, and J. Pycock, Practically Accomplishing Immersion: Cooperation in and for Virtual Environments, in Proceedings of the ACM 1996 Conference on Computer Supported Cooperative Work, M.S. Ackerman, Editor. 1996, ACM: NY. p. 380-389.

[4] Bowers, J., J. Pycock, and J. O'Brian. Talk and Embodiment in Collaborative Virtual Environments. in Proceedings of CHI '96, Vancouver, Canada. 1996. NY: ACM Press.

[5] Button, G., ed. Technology in Working Order: Studies of Work, Interaction, and Technology. . 1993, Routledge: London \& New York.

[6] Denzin, N.K. (ed.), Handbook of Qualitative Research. 1994, California, USA: Sage Publications.

[7] Earle, N. and C. Beardon. The Role of Obligation within Virtual Encounters. in Collaborative Virtual Environments '98: CVE'98. 1998. University of Manchester, UK. 17-19 June 1998.

[8] Haraway, D., A Cyborg Manifesto: Science, Technology, and Socialist-Feminism in the Late Twentieth
Century, in Simians, Cyborgs and Women: The Reinvention of Nature. 1991, Routledge: New York, USA. p. 149-181.

[9] Haraway, D., The Ironic Dream of a Common Language for Women in the Integrated Circuit: Science, Technology, and Socialist Feminism in the 1980s or A Socialist Feminist Manifesto for Cyborgs., in Simians, Cyborgs and Women: The Reinvention of Nature. 1991, Routledge: NY. p. 149-181.

[10] Heath, C. and P. Luff, Convergent activities: Line control and passenger information on the London Underground, in Communication and Cognition at Work, Y. Engestrom, \& Middleton, D., Editor. 1996, Cambridge University Press: N.Y. p. 96-129.

[11] Hindmarsh, J., et al. Fragmented Interaction: Establishing mutual orientation in virtualenvironments. in CSCW'98: Conference on Computer Supported Cooperative Work. 1998 (forthcoming). Seattle: ACM.

[12] Jeffrey, P. and G. Mark. Constructing Social Spaces in Virtual Environments: A Study of Navigation and Interaction. in Workshop on Personalised and SocialNavigation in Information Space. March 16-17. 1998. Stockholm: Swedish Institute of Computer Science:

[13] Lawlay, E.L., Computers and the Communication of Gender 28.3.1998 http://www.itcs.com/elawley/gender.html

[14] Robinson, M. Design for unanticipated use in ECSCW '93 (3rd. European Conference on Computer Supported Cooperative Work). 1993. Milan, Italy: Kluwer.

[15] Schmidt, K. and L. Bannon, Taking CSCW Seriously: Supporting Articulation Work. CSCW, 1992. 1(1): p. 740.

[16] Stone, A.R., Will the Real Body Please Stand Up?: Boundary Stories about Virtual Cultures, in Cyberspace, First Steps, M. Benedikt, Editor. 1992, MIT Press: Cambridge, MA.

[17] Stone, A.R., The War of Desire and Technology at the Close of the Mechanical Age. 1996, Ca., Mass.: MIT.

[18] Suchman, L., Centers Of Coordination: A Case And Some Themes, in Discourse, Tools, and Reasoning, R.S. L. Resnick, and C. Pontecorvo, Editor. in press, Springer-Verlag.

\footnotetext{
${ }^{6} \mathrm{We}$, in common with many other non-paying users, treated AW as an immutable world. We are aware that for members it is mutable.
} 